\title{
The quality of notification of congenital malformations
}

\author{
E G KNOX, E H ARMSTRONG, AND R LANCASHIRE
}

From the Department of Social Medicine, The Medical School, University of Birmingham, Edgbaston, Birmingham B15 2TJ

SUMmaRY The United Kingdom Congenital Malformations Notification Scheme began in 1964. It is based on notes added to birth notification forms. In Birmingham, a local scheme based on multiple sources has been run in parallel for the last 20 years. The national notification scheme records malformations noted up to the age of 7 days, whereas the Birmingham scheme collects information up to the age of 5 years. A case by case record linkage of the two registers was carried out. This operation revealed the essential completeness of the multiple-source register but gross defects among notifications. The extent and nature of the deficiencies are described. They include defects of ascertainment of malformed infants and of major additional malformations in those infants who are in fact notified, overnotification of infants without significant malformations, and misclassification of the major malformations that were, in fact, notified. The defects arise partly from the defective design of the national scheme and partly from defective implementation and a lack of designated supervisory responsibilities. The main requirements for a scheme that could indeed be relied upon to meet its monitoring objectives are set out.

The thalidomide epidemic of 1962 pin-pointed the need to monitor the incidence of malformations. Two main methods were proposed and discussed. The first was a general notification system covering the whole country. The second was a scheme of intensive surveillance limited to a few large centres, such as the existing Birmingham and Liverpool registers, on which the eventual identification of the thalidomide epidemic in the UK had in fact depended. The requirements for prompt notification and large numbers, and the possibility of geographical heterogeneity, led to a preference for the first. A national congenital malformation notification scheme became operational in 1964 , and selected results have been published regularly by the Office of Population Censuses and Surveys since that time. ${ }^{1}$

No explicit decisions were reached regarding the second scheme, relating to the two existing registers, and no support was offered. Both, however, have survived up to the present time on an ad hoc basis, and the register relating to Birmingham residents has been maintained continuously by the Department of Social Medicine at the University of Birmingham since 1950. Its importance for our present purposes is that it enables us to calibrate the completeness and accuracy of national notifications and to assess their capability for meeting monitoring objectives.
There are some prior grounds for concern about the accuracy of the national scheme. They are as follows:

Firstly, although the notification scheme is linked with the statutory requirement for the medical attendant to notify the birth, the notification of any malformation is itself voluntary. Even the statutory part of the process is non-standard, and the arrangements vary between different health authorities. The only standard part of the system is the process whereby the health authorities notify OPCS (through forms SD56 and SD56a). There are no arrangements for the routine quality control with respect to completeness or accuracy at any stage. There are no specific district or regional responsibilities for supervision of these aspects.

Secondly, the OPCS registers only those malformed children who are notified within seven days of birth, and there are no arrangements for including defects that become evident after that time, or for excluding suspected malformations which are later shown not to have warranted notification, or for modifying the diagnosis when more accurate information has become available.

Thirdly, inaccuracies have indeed been noted. Between 1964 and 1972, the Birmingham Congenital Malformations Registration Scheme, 296 
which was then operated jointly by the University Department of Social Medicine and the Birmingham Public Health Department, reported its results annually in the Report of the Medical Officer of Health. (Regular local reporting on the state of the public health in the UK ceased after 1973.) These comparisons showed consistent net under reporting to OPCS.

The purpose of the present paper is to examine the quality and accuracy of notification in detail and to assess how far the present scheme meets and can meet its objectives.

\section{Material and methods}

THE BIRMINGHAM REGISTER

The University of Birmingham Department of Social Medicine has for many years maintained two parallel registers, which we shall refer to as the Birmingham Malformation Register (BMR) and the Birmingham Birth Register (BBR). The BMR is an elaborated subset of the BBR. Entries to both registers are based on birth notifications, but data are also obtained from other sources. These sources supply much additional material and provide for substantial cross-checking of many important elements.

Notifications of birth are made on monthly sheets from the hospitals, and separate forms from the general practitioners, on both of which the details of any malformations are also recorded. For the live births, the additional sources of data are the health visitor records, the "defect" registers maintained by health authorities, and, where necessary, maternity hospital or other hospital records. Where a malformation is recorded on the birth notification form, and where the diagnosis is definite and corresponds with a specific and "significant" ICD malformation code, this coding is accepted. However, where the class of malformation is incompletely specified or ambiguous, or where there are discrepancies between alternative data sources, the maternity hospital records or other hospital records or necropsy reports are inspected directly. Ill defined categories, even when they are ICD listed (such as "other anomalies of...."), are BMR coded only after a detailed review of the hospital notes and/or the necropsy report. Inconclusive notes such as "heart murmur," and minor items such as skin tags, naevi, sacral dimples, ichthyosis, and minor abnormalities of the hair or nails, do not qualify for inclusion under BMR, despite the existence of ICD codes for some of them. Other classes included within ICD but excluded from BMR are undescended testis and infantile hypertrophic pyloric stenosis.

Annual surveillance is subsequently made of the Regional Hospital Activity Analysis (HAA) computer files with respect to Birmingham residents under 5 years of age showing a malformation code against the principal diagnosis or any of the first three secondary diagnoses. The acceptance rules described above are applied, and indefinite or ambiguous diagnoses, or codes which fail to correspond with earlier sources, are recoded after careful review of original records. The scheme has been described in detail elsewhere. ${ }^{2}$

The only malformations that are likely to be missed among children of Birmingham residents delivered in the West Midlands Region and continuing to live in Birmingham are those not diagnosed within seven days of birth, not noted by a health visitor during the first year, and not admitted to any hospital within Birmingham before the age of 5 years.

\section{THE NATIONAL SCHEME}

Notification to OPCS depends solely on the birth notification form, from which details are copied by local authority clerical staff to OPCS forms SD56 and SD56a without any review process. Guidance is obtained from the OPCS nominal/numeric coding system, which is printed on the reverse of these forms. These classes include some of the items excluded from BMR, and even one or two which are not included within the current ICD system for congenital anomalies, for example, hydrocele. These notifications provide the sole basis for the published OPCS tabulations; that is, they are not linked or merged with stillbirth or death certificates. The published data are arranged under nine main malformation groups, which we shall subsequently refer to as the "monitor groups," and the published OPCS data for Birmingham for the years 1972 to 1978 are given in table 1 .

The nine monitor groups do not correspond exactly with the main numeric groups printed on the reverse of the OPCS notification forms, and several

Table 1 Congenital malformations in Birmingham* 1972-8: Published data in OPCS monitor groups

\begin{tabular}{|c|c|c|c|c|c|c|c|c|c|}
\hline \multicolumn{2}{|c|}{$\begin{array}{l}\text { Malformation } \\
\text { group }\end{array}$} & \multirow{2}{*}{$\frac{1972}{50}$} & \multirow{2}{*}{$\frac{1973}{38}$} & \multirow{2}{*}{$\begin{array}{c}1974 \\
50\end{array}$} & \multirow{2}{*}{$\frac{1975}{44}$} & \multirow{2}{*}{$\frac{1976}{41}$} & \multirow{2}{*}{$\begin{array}{c}1977 \\
40\end{array}$} & \multirow{2}{*}{$\begin{array}{c}1978 \\
54\end{array}$} & \multirow{2}{*}{$\begin{array}{c}1972- \\
1978 \\
317\end{array}$} \\
\hline 1 & CNS & & & & & & & & \\
\hline 2 & Eye & 3 & 3 & 6 & 3 & 7 & 4 & 2 & 28 \\
\hline 3 & Ear & 17 & 20 & 6 & 13 & 23 & 18 & 18 & 115 \\
\hline 4 & Cleft lip/palate & 27 & 17 & 25 & 14 & 26 & 15 & 22 & 146 \\
\hline 5 & Intestines & 18 & 19 & 10 & 17 & 18 & 18 & 21 & 121 \\
\hline 6 & Cardiovascular & 53 & 44 & 28 & 48 & 48 & 48 & 44 & 313 \\
\hline 7 & External genitalia & 27 & 26 & 18 & 26 & 25 & 30 & 30 & 182 \\
\hline 8 & Limbs & 158 & 167 & 172 & 163 & 179 & 161 & 202 & 1202 \\
\hline 9 & Chromosomes & 17 & 20 & 13 & 14 & 18 & 27 & 16 & 125 \\
\hline \multicolumn{2}{|c|}{ Total } & 370 & 354 & 328 & 342 & 385 & 361 & 409 & 2549 \\
\hline
\end{tabular}

*Including Sutton Coldfield from 1974 onwards. 
numeric classes are excluded from the published data. Some of the excluded material corresponds with that excluded from BMR, but several major malformations are also omitted. The correspondences between the monitor groups, the OPCS notification classes, the ICD codes, and the BMR acceptance criteria are therefore inexact and complicated. The main relations are indicated in the Appendix.

\section{LIN KA GE}

OPCS supplied us with a listing of their coded records of all cases notified to them in the years 1972-8 by the Birmingham Area Health Authority or (pre-1974) the Birmingham Public Health Department. Our basic investigative method was a case by case collation of the two registers. The record linkage was performed partly through computer matching and partly by visual checking of those pairs of records which were successfully matched by the computer, and of those single records which appeared in one list but not in the other.

The main items on which record linkage between the registers was performed were the dates of birth of the infant and of the mother, the area code numbers of the mother's usual residence and of her place of delivery, and the unique record identification number allocated by the Area Medical Officer and listed both in the OPCS and the BMR files. The linkage process was carried out entirely on the basis of coded particulars and without recourse to identifying individual patients by name or by exact address. Indeed, notifications to OPCS do not include names.

\section{Results}

We present our results under five main headings relating to:

1 infants whose records were identified in one or other of the two lists, or in both;

2 notified individual malformations included within the nine monitor groups;

3 notified malformations falling outside the nine monitor groups;

4 failures of ascertainment and notification;

5 temporal changes in accuracy and completeness of notification.

ASCERTAINMENT OF MALFORMED INFANTS Technical and administrative discrepancies

The first of these related to boundary changes. The later OPCS data referred to the post 1974 Birmingham boundaries, which included Sutton Coldfield, while the BMR register retained the original more restricted boundary. There were $\mathbf{9 0}$ malformed Sutton Coldfield births on the OPCS list.
For purposes of comparing the two registers they were excluded.

A further 15 women were "lost" to BBR because they were delivered outside the Birmingham area and because their subsequent "transfers in" were delayed. Several OPCS notifications were based on birth notifications which were subsequently discovered to be "duplicated." In a few other cases the note of a malformation on the birth notification sheet had subsequently been marked as "cancelled," presumably after the discovery of an error of classification or identification, or perhaps a "transfer out," and presumably without the correction having been notified to OPCS.

All these infants were excluded from the combined lists for purposes of subsequent comparison. There were 41 such "technical" exclusions in addition to the 90 excluded Sutton Coldfield births from an original OPCS total of 3286 malformed infants.

In the course of these searches we also discovered three infants notified to OPCS, all with talipes, all subsequently confirmed through reference to original records, where BBR had not receiveds notification of either the malformation or the birth. These three omissions represent the only true failureso to ascertain a malformation to emerge from the record linkage process.

\section{Notification errors}

The correspondences between the two lists, following the "technical" exclusions, are shown in table 2 . The 3160 infants on the BMR list are shown in the first row, and the 3152 registered with OPCS are shown in the first three columns. There were 990 clear "false negatives" consisting of infants known by BMR to have significant malformations, yet who were not known to OPCS at all. A further 414 were notified on the basis of trivial defects which, on the basis of the record itself, BMR would have regarded as non-significant, and which OPCS, too, would also presumably have excluded from any count of major malformations. However, 28 of these 414 infants did in fact have additional significant defects not notified to OPCS, thus augmenting the number of false negatives from 990 to 1018 .

Of the 2325 infants notified as having a malformation in one of the nine monitor groups, 336 did not in fact have a significant malformation. They can be regarded as clear "false positives." Of the total of 3152 infants known to OPCS, 982 did not have a malformation acceptable to BMR. Although this could be taken to represent a very substantial false positive rate, the available data would enable OPCS to exclude many of them. However, one group of 413 notified infants had indeterminate diagnoses which fell outside the monitor groups, but whose coding 
Table 2 Malformed infants in Birmingham 1972-8: Correspondences between OPCS and BMR lists following "technical" and "administrative" exclusions

\begin{tabular}{|c|c|c|c|c|c|}
\hline \multirow[b]{2}{*}{$B M R$} & \multicolumn{5}{|l|}{ OPCS } \\
\hline & $\begin{array}{l}\text { Malformation present } \\
\text { in } 9 \text { monitor groups }\end{array}$ & $\begin{array}{l}\text { Other recorded } \\
\text { malformation }\end{array}$ & $\begin{array}{l}\text { Non-significant } \\
\text { defect }\end{array}$ & Not recorded & Total \\
\hline $\begin{array}{l}\text { Significant malformation } \\
\text { No significant malformation } \\
\text { Total }\end{array}$ & $\begin{array}{l}1989 \\
336^{*} \\
2325\end{array}$ & $\begin{array}{l}153 \\
260 \\
413\end{array}$ & $\begin{array}{r}28 \\
386 \\
414\end{array}$ & $\frac{990}{990}$ & $\begin{array}{r}3160 \\
982 \\
4142\end{array}$ \\
\hline Total & & 3152 & & & \\
\hline
\end{tabular}

${ }^{*}$ Excluding the 3 cases of missed talipes described in the text.

would not allow OPCS to treat them as clearly non-significant.

Because of these difficulties it is not possible to represent false positive and false negative rates in a uniquely meaningful manner. However, if we treat the first two columns of table 2 as "notified significant" and the third and fourth columns as "not notified significant," then we could attribute to the former class a false negative rate of $32.2 \%$ $(1018 / 3160)$ and a false positive rate of $21.8 \%$ $((336+260) /(2325+413))$.

\section{MONITORED MALFORMATIONS}

We refer in this section to those malformation groups shown in table 1 . Table 3 sets out the correspondences and non-correspondences between the two systems.

Some of the discrepancies spring from differences in taxonomic practice. Thus, although both systems generally classify infants with multiple malformations under all relevant headings, there are some differences of procedure. For example, BMR did not record talipes when it was secondary to another malformation such as spina bifida, whereas OPCS did. Similarly, where a specific syndrome was recorded, and where specific components of the syndrome were separately listed, BMR classified the malformation only under the syndrome, whereas OPCS classified under both headings. For example, congenital heart disease, recorded separately as a concomitant of Down's syndrome, and cleft palate, recorded separately alongside Pierre Robin syndrome, were itemised separately by OPCS but not by BMR.

With these reservations the main features of table 3 are as follows:

Central nervous system

There were 268 concordant allocations to "CNS malformation." Almost all of them (250) were also recorded concordantly according to type as

Table 3 Individual malformations ascertained in Birmingham infants 1972-8

\begin{tabular}{|c|c|c|c|c|c|c|c|c|c|c|}
\hline \multirow[b]{2}{*}{$\begin{array}{l}\text { OPCS } \\
\text { monitor groups }\end{array}$} & \multirow[b]{2}{*}{$\begin{array}{l}\text { OPCS/BMR } \\
\text { concordant } \\
\text { for group } \\
\text { (a) }\end{array}$} & \multicolumn{3}{|c|}{$\begin{array}{l}\text { Recorded by OPCS only } \\
\text { Excluded by BMR because: }\end{array}$} & \multirow[b]{2}{*}{$\begin{array}{l}\text { OPCS } \\
\text { total } \\
(e) \\
(a+b+c+d)\end{array}$} & \multicolumn{2}{|c|}{$\begin{array}{l}\text { Recorded by BMR only } \\
\text { Excluded from OPCS because: }\end{array}$} & \multirow[b]{2}{*}{$\begin{array}{l}\text { BMR } \\
\text { total } \\
(h) \\
(a+f+g)\end{array}$} & \multirow[b]{2}{*}{$\begin{array}{l}\text { Sensitivity of } \\
\text { notification } \\
(j) \\
(a / h) \quad(b+\end{array}$} & \multirow[b]{2}{*}{$\begin{array}{l}\text { Proportion } \\
\text { false claims } \\
(k) \\
b+c) /(a+b+c)\end{array}$} \\
\hline & & $\begin{array}{l}\text { Malformation } \\
\text { is in another } \\
\text { group } \\
\text { (b) }\end{array}$ & $\begin{array}{l}\text { No significant } \\
\text { malformation } \\
\text { present } \\
\text { (c) }\end{array}$ & $\begin{array}{l}\text { Admin/ } \\
\text { Techn } \\
\text { reasons } \\
\text { (d) }\end{array}$ & & $\begin{array}{l}\text { Notified to } \\
\text { another group } \\
(f)\end{array}$ & $\begin{array}{l}\text { No } \\
\text { notification } \\
(g)\end{array}$ & & & \\
\hline 1 CNS & 268 & 8 & 24 & 17 & 317 & 19 & 227 & 514 & 0.52 & 0.11 \\
\hline 2 Eye & 12 & 1 & 11 & 4 & 28 & 5 & 18 & 35 & 0.34 & 0.50 \\
\hline 3 Ear & 84 & 5 & 25 & 1 & 115 & 4 & 25 & 113 & 0.74 & 0.26 \\
\hline 4 Cleft lip and palate & 130 & 3 & 4 & 9 & 146 & 3 & 22 & 155 & 0.84 & 0.05 \\
\hline 5 Intestines & 88 & 2 & 26 & 5 & 121 & 7 & 86 & 181 & 0.49 & 0.24 \\
\hline 6 Cardiovascular & 138 & 12 & 150 & 13 & 313 & 12 & 251 & 401 & 0.34 & 0.54 \\
\hline 7 External genitalia & 150 & 1 & 24 & 7 & 182 & 8 & 42 & 200 & 0.75 & $0 \cdot 14$ \\
\hline 8 Limbs & 1016 & 11 & 85 & 52 & $1202^{*}$ & 34 & 235 & 1285 & 0.79 & 0.09 \\
\hline 9 Chromosomes & 116 & 1 & 5 & 3 & 125 & 5 & 33 & 154 & 0.75 & 0.05 \\
\hline Total & 2002 & 44 & 354 & 111 & 2549 & 97 & 939 & 3038 & 0.66 & $0 \cdot 17$ \\
\hline
\end{tabular}

†See text.

*In addition to the four previous columns, this particular total includes three talipes not recorded by BMR and another 35 which were secondary to another major malformation. 
anencephalus, spina bifida, microcephalus, etc. However, BMR recorded an additional 227 CNS abnormalities among infants not known at all to OPCS, and another 19 infants notified to OPCS under another heading and whose CNS malformations were not recorded. They included 90 infants with anencephalus, 50 with spina bifida, 71 with hydrocephalus, and 30 with microcephalus. The overall "sensitivity" of the OPCS system, with respect to all CNS malformations registered by BMR, was $52 \%$.

OPCS also recorded 32 false positives among infants who in fact had either a non-CNS malformation (8), or no significant malformation at all (24). The false positive rate was $11 \%$ of those malformations classified by OPCS as CNS: that is, $32 /(32+268)$. These false positives included infants who in fact had facial palsies, Erb's palsies, cephalhaematomas, cranial and skeletal disorders, convulsions and sacral dimples: and two infants for whom the hospital or necropsy notes supplied neither evidence nor confirmation of a defect of any kind. It is possible that these last two represent errors of identification in the notification process, and the infants who should have been attached to these diagnoses might possibly be among the 227 CNS malformations "not known" to OPCS.

\section{Abnormalities of the eye}

Overall sensitivity here was $34 \%$. Half of the notified malformations were false positives. Only two of 13 cataracts were known (as cataract) to OPCS. The false positives included an omphalomesenteric duct erroneously classified as anophthalmos, cases of protruding or oedematous eyes, cysts, a squint, and suspected abnormalities of the eyelids.

\section{Abnormalities of the ear}

Overall sensitivity in this group was $74 \%$, although the majority of these notifications referred to trivial defects, such as accessory auricles. The false positive rate was $26 \%$. Five of the 30 false positives related to misshapen or low set ears in children with other notified malformations, and the remainder were listed variously as large, small, bat or misshapen ears or as cysts or skin tags, all having been excluded from the BMR system.

\section{Clefts of lip and palate}

Overall sensitivity was $84 \%$, slightly higher in the infants with cleft lip (with or without cleft palate), and slightly lower in those with cleft palate alone. The false positive rate was also satisfactory, only $5 \%$, and two of the seven false positives arose from differences in classification practice between the BMR and OPCS systems. They were "double entries" of Pierre Robin syndrome. The others had either a "high" palate or "split" gums.

\section{Abnormalities of the intestines}

Sensitivity was poor at only $49 \%$ but slightly better for those malformations making an insistent appearance within the first few days of life. Thus, $55 \%$ of tracheo-oesophageal fistulas were notified, together with $71 \%$ of anal atresias. The false positive rate was $24 \%$ although, as in the last section, some of the $\mathbf{2 8}$ false positives were attributable to differences in taxonomic practice. They included five cases of infantile hypertrophic pyloric stenosis which, despite its nature and its exclusion from BMR, is counted as a malformation within ICD. The other false positives included suspected alimentary obstructions which were not subsequently confirmed, enlarged livers, anal fissures, and various minor abnormalities of the mouth and gums.

\section{Cardiovascular disease}

Only $34 \%$ of the cardiovascular anomalies known to BMR were recorded by OPCS. In addition, the false positives exceeded the true positives. The great majority of the 162 false positives were excluded by BMR as transient "heart murmurs" without ac subsequent diagnosis of a malformation having been made. Taxonomic variations contributed only a small element with seven cases of double counting in Down's syndrome. Among the other false positives, pulmonary hypoplasia was notified as pulmonary artery hypoplasia in one child, and some were notified because they had only two vessels in their umbilical cords.

\section{Abnormalities of the external genitalia}

Almost all were hypospadias or epispadias, and overall sensitivity was $75 \%$. The false positive rate was only $14 \%$. The 25 false positives included three children with hydrocele, two with torsion of the testis, a number of minor and non-significant problems related to the size of the phallus (in either sex), and one misclassified karyotypic abnormality.

\section{Abnormalities of the limbs}

These abnormalities included polydactyly, syndactyly, reduction abnormalities, other limb deformities, congenital dislocation of the hip, and talipes. All of them were well ascertained, with an overall sensitivity of $79 \%$ and a high degree of correspondence between the two registers with respect to the allocated subclasses. The false positive rate was $9 \%$. Reference back to original records showed that the largest number of these false positives, 78 in all, were recorded as having hammer toes, overlapping toes, or other insignificant digital abnormalities.

\section{Chromosome abnormalities}

Overall sensitivity was $75 \%, 80 \%$ for Down's syndrome and $52 \%$ for other chromosomal syndromes. The false positive rate was low (5\%) and 
included children with suspected abnormalities which were not subsequently confirmed, and also a misclassified case of osteo-onychodysplasia-the "other" Turner's syndrome.

\section{MALFORMATIONS OUTSIDE THE NINE MONITOR} GROUPS

The nine OPCS monitor groups exclude several major deformities, including exomphalos, hernia, some musculoskeletal disorders, and several varieties of urogenital disorders, including renal agenesis and eventration of the bladder. The content of this group is given in table 4 . The affected infants are to be found mainly in column 2 of table 2 but include others from column 1 with multiple malformations, some of which were outside the monitor groups.

Table 4 Malformations outside the nine monitor groups $1972-8$

\begin{tabular}{|c|c|c|c|c|}
\hline \multirow[b]{2}{*}{ Malformation } & \multicolumn{4}{|c|}{ Classified by } \\
\hline & $\begin{array}{l}\text { OPCS and } \\
\text { BMR }\end{array}$ & OPCS only & $B M R$ only & Total \\
\hline Exomphalos & 20 & 1 & 0 & 21 \\
\hline Diaph./hiatus hernia & 14 & $\mathbf{0}$ & $\mathbf{0}$ & 14 \\
\hline Urogenital & 31 & 15 & 14 & $60^{*}$ \\
\hline Respiratory & 4 & 9 & 7 & 20 \\
\hline Musculoskeletal & 37 & 152 & 42 & $231^{*}$ \\
\hline Other & 31 & 96 & 41 & $168^{*}$ \\
\hline Total & 137 & 273 & 104 & 514 \\
\hline
\end{tabular}

*Infants with two malformations in the same group are counted only once in that group. There were seven infants in this category.

There was excellent correspondence for exomphalos and diaphragmatic hernia and a moderate degree of correspondence for the urogenital disorders. However, the "musculoskeletal" and "other" abnormalities displayed large numbers of positive and negative errors in the OPCS notifications. There was a spate of non-significant musculoskeletal notifications in 1978, with 95 in that year alone. This group was made up largely of reported "clicking hips" which were coded by OPCS to this class. Dislocated hips are recorded with the monitor group concerned with abnormalities of the limbs.

FAILURES OF ASCERTAINMENT AND NOTIFICATION

Part of the failure of the notification system to register significant malformations can be ascribed to the "seven day rule." In table 5 we set out the false negatives according to the timing of entry to the BMR system and according to the type of malformation. We separate those infants of which OPCS had no knowledge at all from those where they had a record of a malformed birth but not of the particular malformation concerned. About half of the negative errors stemmed from late identification, but this was especially relevant in relation to cardiovascular disorders, congenital dislocation of the hip, microcephalus, and hypospadias. There were, however, also substantial failures of notification for many malformations which were evident at birth and recorded by BMR as having been diagnosed at that time. They include anencephalus, spina bifida, hydrocephalus, and alimentary and cardiovascular malformations. The main defects of recording Down's syndrome also related to diagnoses made at birth. These are failures of notification rather than failures of ascertainment or recognition. We suspect that part of the problem may arise from transfer of infants either to special units or to necropsy departments, with subsequent disruption of the normal notification procedure until the infant is returned to normal care, or the case notes to the Records Department, at some time after the seven day limit.

Table 5 refers only to malformations within the nine monitor groups. Columns (a) of table 5

Table 5 Major malformations in the monitor groups: timing of notification failures

\begin{tabular}{|c|c|c|c|c|c|c|}
\hline & \multicolumn{2}{|c|}{ At birth } & \multicolumn{2}{|c|}{ Later } & \multicolumn{2}{|l|}{ Total } \\
\hline & $a$ & $b$ & $a$ & $b$ & $a$ & $b$ \\
\hline Anencephalus & 88 & 2 & $\mathbf{0}$ & 0 & 88 & 2 \\
\hline Spina bifida & 27 & 7 & 13 & 3 & 40 & 10 \\
\hline Hydrocephalus & 34 & 2 & 35 & $\mathbf{0}$ & 69 & 2 \\
\hline Microcephalus & 8 & 2 & 19 & 1 & 27 & 3 \\
\hline Other CNS & $\mathbf{0}$ & 1 & 3 & 1 & 3 & 2 \\
\hline Cataract & 5 & 1 & 5 & $\mathbf{0}$ & 10 & 1 \\
\hline Other eye & 1 & 3 & 7 & 1 & 8 & 4 \\
\hline Accessory auricle & 3 & 1 & 13 & $\mathbf{0}$ & 16 & 1 \\
\hline Other ear & 8 & 3 & 1 & $\mathbf{0}$ & 9 & 3 \\
\hline Cleft lip $+/-$ palate & 9 & 0 & 2 & 0 & 11 & $\mathbf{0}$ \\
\hline Cleft palate & 8 & 3 & 3 & $\mathbf{0}$ & 11 & 3 \\
\hline TOF & 12 & 1 & 1 & $\mathbf{0}$ & 13 & 1 \\
\hline Anal atresia & 7 & 2 & 7 & $\mathbf{0}$ & 14 & 2 \\
\hline Other alimentary & 29 & 2 & 30 & 2 & 59 & 4 \\
\hline Cardiovascular & 90 & 9 & 161 & 3 & 251 & 12 \\
\hline Hypospadias/Epispadias & 9 & 3 & 26 & 1 & 35 & 4 \\
\hline Other external genitalia & 2 & 4 & 5 & $\mathbf{0}$ & 7 & 4 \\
\hline Polydactyly & 18 & 3 & 7 & 1 & 25 & 4 \\
\hline Syndactyly & 9 & 3 & 4 & $\mathbf{0}$ & 13 & 3 \\
\hline Reduction of limbs & 10 & 2 & 2 & $\mathbf{0}$ & 12 & 2 \\
\hline Other limb & 14 & 12 & 4 & 0 & 18 & 12 \\
\hline Congenital dislocation of hip & 17 & 9 & 80 & 2 & 97 & 11 \\
\hline Talipes & 28 & 2 & 42 & $\mathbf{0}$ & 70 & 2 \\
\hline Down's syndrome & 18 & $\mathbf{0}$ & 8 & 0 & 26 & $\mathbf{0}$ \\
\hline Other syndromes & 5 & 2 & 2 & 3 & 7 & 5 \\
\hline Total & 459 & 79 & 480 & 18 & 939 & 97 \\
\hline
\end{tabular}

(a) Cases where OPCS have no knowledge of any type of malformation.

(b) Cases where OPCS have a record of a malformed birth not included in the listed categories detailed in table 1. 
represent infants of whom OPCS had no knowledge at all. Columns (b) represent infants known to OPCS, who should have been included within the indicated monitor groups but whose notification details did not indicate the presence of any "monitor group" malformation. There is a third type of negative error not shown in this table. These are infants with a malformation actually recorded within the monitor groups of table 1, who yet had additional unnotified monitor group deformities. These infants are characterised in table 6. (The recurrence of the total number of 97 in tables 5 and 6 is simply a numerical coincidence; the two types of error are separate.)

Table 6 Failure to notify additional malformations in infants with a primary notification of a major deformity

\begin{tabular}{lccc}
\hline & At birth & Later & Total \\
\hline CNS & 2 & 2 & 4 \\
Eye & 2 & 0 & 2 \\
Ear & 3 & 2 & 5 \\
Cleft lip +/- palate & 7 & 0 & 7 \\
Intestines & 16 & 5 & 21 \\
Cardiovascular & 16 & 11 & 27 \\
External genitalia & 2 & 2 & 4 \\
Limbs & 11 & 7 & 18 \\
Chromosomes & 8 & 1 & 9 \\
Total & 67 & 30 & 97 \\
\hline
\end{tabular}

TEMPORAL VARIATIONS

The year by year relation between the numbers of correct notifications and errors is given in table 7. For this examination we treat the first two columns of the first row of table $2(1989+153)$ as true positive notifications, but only the first column of the second row (336) as false positives. That is, we suppose that the 260 infants in the second column of table 2 might have been correctly distinguished, by OPCS, as having no significant defect. Sensitivities and false positive rates are given in table 7 on this basis. The net under reporting was fairly constant, and no obvious artefactual epidemics occurred as a result of temporal variations of accuracy.

\section{Discussion}

The national system for notifying congenital malformations contains major defects. The taxonomic complexities preclude simple numerical expression. The defects relate to the ascertainment of malformed infants, the ascertainment of major malformations in those infants which are notified, the over notification of infants without significant malformations, and misclassification of the major
Table 7 Temporal variations in error rates 1972-8

\begin{tabular}{llllll}
\hline & $\begin{array}{l}\text { Total } \\
\text { Birmingham* } \\
\text { births } \\
(a)\end{array}$ & $\begin{array}{l}\text { BMR } \\
\text { malformed } \\
\text { infants } \\
(b)\end{array}$ & $\begin{array}{l}\text { Prevalence } \\
\text { per 1000 } \\
\text { total births } \\
(c)\end{array}$ & $\begin{array}{l}\text { OPCS true } \\
\text { positives } \\
(\text { b/a })\end{array}$ & $\begin{array}{l}\text { OPCS false } \\
\text { positives } \\
(e)\end{array}$ \\
\hline 1972 & 15834 & 482 & $30 \cdot 4$ & $327(0 \cdot 68)$ & $51(0 \cdot 16)$ \\
1973 & 14541 & 497 & $34 \cdot 2$ & $317(0 \cdot 64)$ & $46(0 \cdot 15)$ \\
1974 & 13847 & 438 & $31 \cdot 6$ & $276(0 \cdot 63)$ & $30(0 \cdot 11)$ \\
1975 & 12861 & 405 & $31 \cdot 5$ & $274(0 \cdot 68)$ & $61(0 \cdot 22)$ \\
1976 & 12642 & 476 & $37 \cdot 7$ & $326(0 \cdot 68)$ & $51(0 \cdot 16)$ \\
1977 & 12445 & 419 & $33 \cdot 7$ & $291(0 \cdot 69)$ & $51(0 \cdot 18)$ \\
1978 & 12926 & 443 & $34 \cdot 3$ & $331(0 \cdot 75)$ & $46(0 \cdot 14)$ \\
& & 3160 & $33 \cdot 2$ & $2142(0 \cdot 68)$ & $336(0 \cdot 16)$ \\
\hline
\end{tabular}

*Excluding Sutton Coldfield births.

The true positive rate is calculated as $d / b$. The false positive proportion is calculated as $e /(d+e)$.

malformations that were in fact notified.

There is no special reason why Birmingham should be regarded as unrepresentative in these respects. The prior existence and coexistence of a local ascertainment system is unlikely to have contributed to the error rates because the Birmingham Malformation Registry (BMR) assembles its data relatively late and does not compete with OPCS for the same information at the same time. Indeed, if the Birmingham experience is in any way special, the prior existence of appropriate filing and clerical processes, and the early provision and use of semi-automated systems (ie, punch cards) is more likely to have improved the precision and accuracy of local notifications when compared with other areas. The errors revealed in this study probably represent the lower rather than the upper bounds of national variation in these respects.

Some of the errors are consequences of the design of the notification system, and others are failures of implementation. As regards design, it was known from the beginning that national notifications could play no part in detecting epidemics of malformations which did not become clinically evident until after the seventh day of life. The major features of congenital rubella syndrome, for example, would not be detected. It was also known that the scheme was redundant for any malformations which usually present as early deaths or as stillbirths, and where regular perusal of the death certificates and stillbirth certificates would be capable of detecting changes promptly. The utility of the scheme was therefore seen from the outset to be limited to particular classes of malformation.

However, the effects of poor standards of reporting, and the utility of a scheme designed to run in the absence of designated supervisory or quality monitoring responsibilities, were until now a matter for speculation. If Birmingham is at all typical, the 
main conclusions in these respects seem now to be as follows.

For the neural tube defects the accuracy of reporting was poor. As a result the notification of fatal cases is not only redundant but the information obtained through notification is actually less reliable than that obtainable from certificates of stillbirths and deaths. A combination of these certified causes with Hospital Activity Analysis (HAA) records would provide a far more satisfactory ascertainment system for the malformations in this group. The malformations of the eye and the malformations of the ear, as presented in the monitor groups, must also be regarded as almost entirely useless, by reason of late diagnosis, inaccurate reporting, and their generally trivial nature. Cardiovascular disorders also display gross errors of both kinds, added to which they are not in general classifiable with sufficient accuracy in the first seven days to permit monitoring of individual syndromes.

By contrast, several other types of malformation, not readily ascertained from other sources, were notified with fair accuracy. They include clefts of the lip and palate, tracheo-oesophageal fistula, anal atresia, hypospadias, and epispadias. Down's syndrome was also surprisingly well reported. Exomphalos, renal agenesis, and eventration of the bladder, although they are not included within any of the published monitor groups, were also reported with reasonable accuracy. Insofar as a drug-induced (or otherwise induced) epidemic might result in a syndrome which included these components, they constitute cogent grounds for maintaining a notification process. Particular syndromes within otherwise useless groups of notifications could be added to this list; for example, anophthalmos, cyclops, coloboma, and, of course, reduction deformities of the limbs.

Therefore, despite its design defects and its sometimes gross inaccuracies, the national notification system for congenital malformations in the UK has potential uses. That is, a few elements are notified with sufficient accuracy to have real meaning, are not "covered" by alternative information collecting pathways, and are sufficiently uncommon for a moderate increase to evade local clinical-intuitive detection. Properly selected and displayed they would provide a useful, if partial, monitor. However, it is abundantly clear that the scheme also has serious limitations and, because of them, could not be relied upon to meet its objectives.

Nationwide, state-wide, or other large-scale systems for notifying or otherwise ascertaining the occurrence of congenital malformations have been reported from several countries including Finland, ${ }^{3}$ Sweden, ${ }^{4-6}$ Norway, ${ }^{7}$ Hungary, ${ }^{8}$ Australia, ${ }^{910}$ New
Zealand, ${ }^{11}$ United States of America, ${ }^{12}$ Canada, ${ }^{13}$ and Scotland. ${ }^{14}$ Several investigators have tried, as we have, to compare the reliability of information obtained from several different sources. $^{51012-14}$ However, most of these comparisons have relied on contrasting gross rates obtained from different places or through different systems. Very few besides our own (and a previous report based on the Birmingham system $^{2}$ ) have been based on direct case by case matching. Among others conducted in this way, a Swedish study ${ }^{5}$ compared two parallel systems which each ascertained about two-thirds of all cases, while the remainder were detected by only one system or by the other but not by both. Neither system was complete, so the proportion of cases not detected by either was not known. Both systems reported only cases ascertained within six months of birth. Experience in the Canadian Province of Ontario, ${ }^{13}$ like the earlier Birmingham study, ${ }^{2}$ described correspondences between information collected from different individual sources. Its terms of comparison were therefore different from those reported here. The conclusions were, however, the same, and the same as those of other investigators; ${ }^{26}$ there is no real substitute for a system based on multiple sources, assembled through record linkage procedures and operated by skilled staff. Without such arrangements the evidence shows that genuine malformations will be under reported and inaccurately classified and that a high proportion of false positives will create a proneness to false alarms. ${ }^{6}$

Record linkage requires record identifiers, either personal identifiers such as names and dates of birth or numeric codes. The schedules and methods described by several investigators make it clear that a number of existing systems do indeed employ identifiers of these kinds, ${ }^{3-10}{ }^{13}$ although not all of the systems necessarily use them effectively. A great technical weakness of the British system is that automated record linkage procedures are not even possible on a routine national basis. The record-identifier assigned by the District Medical Officer, and included on the notification form, is not included on death certificates or stillbirth certificates or on hospital admission records. It can be used only for occasional ad hoc studies at local level. It is thus clear that it is not only the quality of implementation of the UK notification system, but also its design, which is urgently in need of review.

The main requirements for an effective scheme which could indeed be relied on to meet its objectives are:

1 the incorporation of nominal and other identification data, sufficient to permit collation of notifications with data recorded on 
stillbirth and death certificates, as well as Hospital Activity Analysis records;

2 the establishment of secondary notification procedures at about one year, and perhaps five years, also linkable, for accessing malformations not easily recognised or classified within the first seven days, and for amending the classification of those already notified;

3 the establishment of local arrangements, probably at regional level, for supervision and quality control.

The last requirement might involve the establishment and maintenance of special registers in a few large centres associated with the regional supervisory responsibilities. Indeed, the major part of the national monitoring service might then profitably be associated with regional centres and managed under professional, that is, medical, supervision. This would relieve the NHS of the need to subcontract this part of its health monitoring responsibilities to an outside body, and ameliorate the confidentiality problems which at present effectively obstruct linkage procedures and nullify the objectives of the system.

This work was supported by a DHSS Health Services Research Programme grant. We are especially grateful to OPCS for supplying necessary material.

\section{References}

${ }^{1}$ Office of Population Censuses and Surveys (1972-1978) Congenital malformation statistics: Notifications. Series MB3, HMSO.

${ }^{2}$ Leck I, Record RG, McKeown T, Edwards JH. The incidence of malformations in Birmingham, England, 1950-1959. Teratology 1968; 1: 263-80.

${ }^{3}$ Saxen L, Klemetti A. The Finnish register of congenital malformations. Acta Univ Carol (Med Monogr) Praha 1973; 56: 23-30.

${ }^{4}$ Kallen B, Winberg J. A Swedish register of congenital malformations: experience with continuous registration during 2 years with special reference to multiple malformations. Pediatrics 1968; 41: 765-76.

${ }^{5}$ Ericson A, Kallen B, Winberg J. Surveillance of malformations at birth: a comparison of two record systems run in parallel. Int J Epidemiol 1977; 6: 35-41.

${ }^{6}$ Kallen B, Winberg J. Dealing with suspicions of malformation frequency increase: experience with the Swedish register of congenital malformations. Acta Pediatr Scand (Suppl) 1979; 275: 66-74.

${ }^{7}$ Bjerkedal T, Bakketeig LS. Surveillance of congenital malformations and other conditions of the newborn. Int $J$ Epidemiol 1975; 4: 31-6.

${ }^{8}$ Czeizel A. The Hungarian congenital malformation register. Acta Univ Carol (Med Monogr) Praha 1973; 56: 53-7.

${ }^{9}$ Seward JF, Stanley FJ. Congenital malformations register in Western Australia. Med J Aust 1981; 1: 218-9.

${ }^{10}$ Bower C, Stanley FJ. Western Australia congenital malformations register. Med J Aust 1983; 2: 189-91.

${ }^{11}$ Foster FH. Congenital anomaly monitoring in New Zealand 1979-81. NZ Med J 1982; 95: 780-1.

${ }^{12}$ Edmonds LD, Layde PM, James LM, Flynt JW, Erickson JS, Oakley GP Jr. Congenital malformations surveillance: two American systems. Int J Epidemiol 1981; 10: 247-52.

${ }^{13}$ Newcombe HB. Pooled records from multiple sources for monitoring congenital anomalies. Brit J Prev Soc Med 1969; 23: 226-32.

${ }^{14}$ Cole SK. Evaluation of a neonatal discharge record as a monitor of congenital malformations. Community Med 1983; 5: 21-30.

\section{Appendix}

This appendix shows the correspondence between the OPCS notification classes, the groups of malformations enumerated in the OPCS monitor tabulations, and the BMR acceptance criteria. The numerical OPCS monitor group codes (1-9) given in the following table correspond with the successive titles shown in text table 1 .

\begin{tabular}{|c|c|c|c|c|c|}
\hline \multicolumn{2}{|c|}{ OPCS notification group } & \multicolumn{2}{|c|}{ OPCS notification code and name } & \multirow{2}{*}{$\frac{\text { OPCS monitor group }}{1}$} & \multirow{2}{*}{$\begin{array}{l}\text { BMR acceptance } \\
+\end{array}$} \\
\hline 0 & Central nervous system & 0.1 & Anencephalus & & \\
\hline & & 0.8 & Spina bifida & 1 & + \\
\hline & & 0.4 & Hydrocephalus & 1 & + \\
\hline & & 0.5 & Microcephalus & 1 & + \\
\hline & & 0.6 & Other specified malformations of brain or spinal cord & 1 & + \\
\hline & & 0.9 & Unspecified malformations of brain, spinal cord, and nervous & & \\
\hline & & Not & $\begin{array}{l}\text { system } \\
\text { defined-0.0,0.2, } 0.3,0.7\end{array}$ & 1 & - \\
\hline \multirow[t]{4}{*}{1} & Eye and ear & 1.1 & Anophthalmos and microphthalmos & 2 & + \\
\hline & & 1.3 & Cataract and corneal opacity & 2 & + \\
\hline & & 1.2 & Other specified malformations of eye & 2 & + \\
\hline & & 1.0 & Unspecified malformations of eye & 2 & - \\
\hline
\end{tabular}




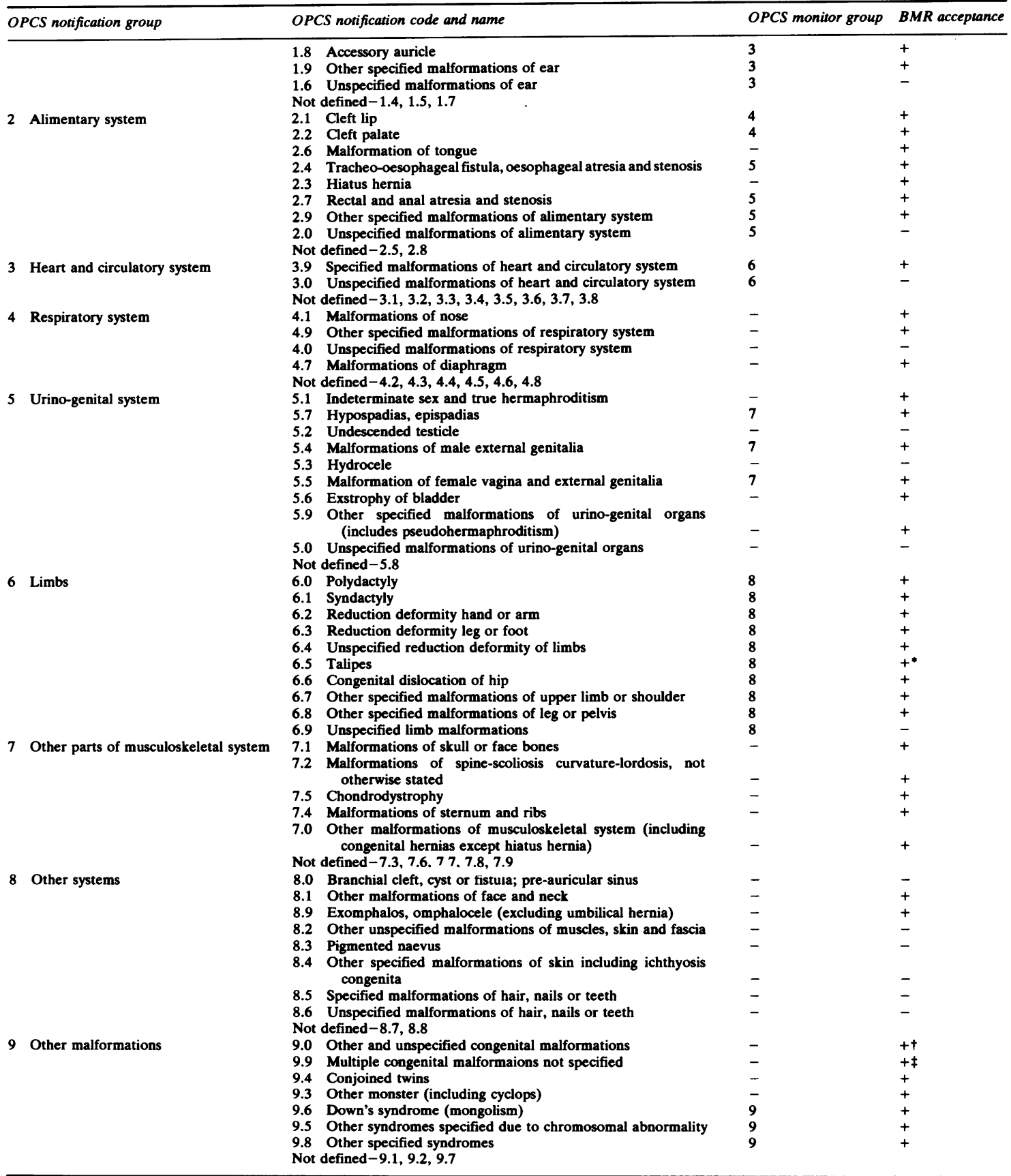

"Except where secondary to a major malformation

†Accepted if "other" and specified: not if unspecified.

$\ddagger$ Only fatal malformations without necropsy. 